\title{
Una nueva herramienta lexicográfica. CONCORDANTIA ORTEGIANA: Concordantia in José Ortega y Gasset opera omnia. Posibilidades de investigación: los casos de ameba y de anastasio
}

\author{
JOSÉ RAMÓN CARRIAZO RUIZ \\ Centro de Estudios Orteguianos. Fundación Ortega y Gasset \\ Instituto Historia de la Lengua - Cilengua \\ Universidad de La Rioja
}

La lexicografía española ha entrado en el siglo XXI con ímpetu renovado y una buena porción de tareas pendientes, que plantean un panorama muy interesante para su desarrollo en los próximos años. El empleo de herramientas informáticas y la popularización de los soportes digitales, acaecida esta a finales de la pasada centuria, ponen por delante unas posibilidades para el investigador y el usuario de recopilaciones léxicas antes inimaginables para ellos. Los viejos formatos se adaptan a las nuevas necesidades y posibilidades; así ha ocurrido con las concordancias.

Las primeras concordantiae fueron las de la Biblia, el gran relato, conjunto de libros y textos -corpus-, más que libro. Las concordantiae se concibieron entonces como instrumentos de trabajo para los hermeneutas. La Biblia fue, por lo tanto, el primer corpus textual, y las concordantiae la fuente, sin más, para extraer sus sentidos, su riqueza oculta. El formato se fue adaptando después a otros corpus textuales, en el ámbito, principalmente, de la filología clásica, pero también en áreas de conocimiento como la literatura romance, la lingüística de corpus y la historia del pensamiento.

Muy recientemente ha aparecido la Concordantia in José Ortega y Gasset opera omnia (en adelante $C O$ ), publicación a la que vamos a dedicar las páginas que siguen. Se trata de una recopilación completa de todo el vocabulario de José Ortega y Gasset, posiblemente el más importante pensador español del siglo XX, con lo que eso implica de acopio de datos cuyo conocimiento es fundamental para la historia del vocabulario filosófico y científico español de los últimos cien años. Ortega fue un gran divulgador de la cultura de su tiempo, no sólo en su obra, sino también en sus empresas culturales (El Sol, Calpe, Revista de Occidente); este papel lo convierte en pieza clave para la comprensión del proceso innovador experimentado por el léxico español recientemente.

En este trabajo analizaremos primero la actualidad y novedades que presentan las concordancias como género lexicográfico, cuya evolución en las últimas décadas se ha visto claramente influida por la estandarización de las herramientas y soportes informáticos. Una vez contextualizada, el análisis se centrará en la $C O$ como producto lexicográfico, tanto en los aspectos relativos a su estructuración, como a su contenido; es decir, su microestructura y su macroestructura. Por último, y para demostrar la gran potencialidad de esta nueva herramienta, realizaremos un estudio lexicológico del vocabulario orteguiano, centrado en los tecnicismos neológicos amiba y de anastasio. 


\section{ACTUALIDAD DE LAS CONCORDANCIAS EN LA LEXICOGRAFÍA: ÚlTIMAS APORTACIONES}

La reciente publicación de la $C O$ en 2004, a las puertas de la celebración del cincuentenario de la muerte del filósofo, ha acercado la lexicografía a los pupitres de los lectores y estudiosos del pensamiento español de la primera mitad del Veinte. Sólo por ello, merece la pena dedicarle unas breves páginas a esta nueva herramienta hermenéutica. Aprovecharemos, además, la circunstancia para repasar las últimas aportaciones editoriales en el campo de las concordancias, su historia y su trascendencia en el mundo de la filosofía.

La historia de las concordancias tiene ya varios siglos de recorrido. El recurso a la ordenación alfabética del léxico de un libro ha sido utilizado por hermeneutas para la elaboración de vocabularios, diccionarios, gramáticas y, en general, para la enseñanza de lenguas desde la baja Edad Media. ${ }^{1}$ El griego y el latín han mantenido, desde entonces, una tradición ininterrumpida de concordancias léxicas, en buena medida fuentes para el conocimiento del vocabulario y la elaboración de repertorios del mismo.

Desde los años setenta de la centuria pasada esta tradición ininterrumpida ha sufrido, merced a la introducción de la informática, una auténtica renovación, a la cabeza de la cual volvemos a encontrar a la filología clásica. ${ }^{2} \mathrm{~A}$ mediados de ese decenio empezaron a recogerse los primeros frutos de este trabajo (Warwick 1975). Ya desde antes se pueden señalar algunas aportaciones realizadas desde la filología románica, como las concordancias de Dante (Wilkins y Bergin 1965), o desde las literaturas germánicas (Shakespeare: Spevack 1973). En España, ya en los noventa, deben señalarse las monumentales concordancias de Lebrija (García-Macho 1996).

La filología latina aprendió a hacer concordancias y a utilizarlas para la enseñanza del latín y la difusión de la filosofía antigua, labor en la que sigue en buena medida empeñada. ${ }^{3}$ Más recientemente la lingüística de corpus se ha ocupado de aprovechar el recurso interpretativo diseñado y desarrollado por los latinistas, y aplicarlo a variados conjuntos documentales. ${ }^{4} \mathrm{Se}$ oye poco de concordancias, sin embargo, en otras áreas de las ciencias sociales, aunque se han

1 Francisco Ruiz, en su Índice, aplicó a la obra de Aristóteles técnicas que ya entonces tenían cierta solera en el estudio de la Biblia: suele considerarse a San Antonio de Padua y Hugo de Santo Caro introductores respectivamente, en el siglo XIII, de las llamadas concordancias reales y de sus contradistintas, las concordancias verbales (con todos los precedentes que se quieran: loci paralleli, glossae interlineares...). Podríamos seguir desde entonces esas dos tradiciones de técnicas paralelas, a veces enfrentadas, otras confluyentes o incluso superpuestas: la de quienes se fijan más en la cosa, en el significado (el contenido y los resúmenes, las materias y sus tablas, clasificaciones y jerarquias, thesaurus, \&c.), y la de quienes se limitan a las palabras, al significante (las concordancias en sentido estricto, las actuales búsquedas en texto libre). Por lo demás, la distinción saussuriana entre significado y significante no la entendemos como una dicotomía absoluta, puesto que hay significados que están referidos a los mismos significantes (pongamos por caso «letra gótica», o, en general, los signos autónimos) y hay significantes que generan su propio significado (como ocurre con los términos tautogóricos). (http://www.filosofia.org/i-comp.htm)

2 El 28 de marzo de 1971 el profesor Theodore F. Brunner lanzó la idea, desde la Universidad de California, de crear un Thesaurus Linguae Graecae [TLG]. Colaboradores de todo el mundo comenzaron a verter a formato electrónico todos los textos escritos en griego que se conservan, siguiendo las ediciones críticas más autorizadas. A finales de 1989 el TLG acumulaba 65 millones de palabras de 9400 obras de 3165 autores. Este fondo está disponible en cintas magnéticas y, casi en su totalidad en un sólo CD-ROM (la versión de diciembre de 1992 ocupa $477 \mathrm{Mb}$ ). El proyecto inicial pretendía cubrir el período desde Homero hasta el año 600 de nuestra era, más adelante se decidió continuarlo hasta 1453 (http://www.filosofia.org/i-comp.htm).

3 Como prueban los abundantes ejemplos de reciente publicación (Iso 1987 y 1991, Magallón García 1993).

4 En la línea de las publicaciones anteriormente citadas y también en el ámbito latino, puede mencionarse Yagüe Ferrer (1995). 
publicado interesantes ejemplos en los últimos años (San Ignacio de Loyola, ${ }^{5}$ autores náuticos del Siglo de Oro... ${ }^{6}$ y es muy posible que haya otras).

Es más: las concordancias en libro han dado paso a las concordancias como herramienta electrónica, gracias a los avances de la informática aplicada al proceso de textos y la lingüística computacional. Hoy en día por concordancias se entiende tanto el libro que las contiene como el programa informático que, a partir de un texto convenientemente marcado, construye el índice alfabético de los términos del mismo. Es el caso de El Quijote (reeditado con motivo del centenario), el Corpus Diacrónico del Español (CORDE) o el Corpus de Referencia del Español Actual (CREA), ejemplos de concordance builder asociado a un corpus textual en internet.

Los programas de construcción de concordancias (concordance builders) suelen producir unos listados de voces, con varias posibilidades de ordenación, pero sin distinguir palabras o términos; son listados de ítems léxicos -voces- entendidos como cadenas de caracteres separadas de otras cadenas de caracteres por un blanco o determinados signos ortográficos, caracteres a su vez definidos previamente (signos de puntuación). Generalmente, incluyen también la posibilidad de decodificar una serie de marcas textuales internas, en lenguaje ASCI, que sirven para obtener la localización de cada cadena de caracteres. En resumen, lo que un programa para construir concordancias nos sirve es un listado de ejemplos, citas o, más técnicamente, ocurrencias de palabras. Para convertir este listado de ocurrencias en un producto lexicográfico con un grado mayor de refinamiento es preciso proceder a su lematización.

En definitiva, las concordancias, desde la Vulgata de San Jerónimo acá, se han desarrollado hasta convertirse en un hábito interpretativo más en ámbitos como la gramática, la enseñanza de lenguas, la ecdótica, la lexicografía, la semántica, el estilo, la historia de las ideas, de la cultura... En esta línea se han elaborado concordancias de los textos de grandes filósofos: Platón, Aristóteles, Santo Tomás... y ahora José Ortega y Gasset, que se incorpora a esta corriente al tiempo que otros autores de la cultura hispánica.

\section{CO: MICRO Y MACROESTRUCTURA}

La $C O$ se presenta en doble soporte: un libro y un CD-ROM. En esto se parece al Quijote de la editorial crítica, publicado en 1998. Evidentemente, el texto base, en este caso, no se recoge en el libro, pues se trata de las obras completas de Ortega. El texto de la concordancia aparece íntegro en el CD, en formato PDF (AcrobateReader es necesario en el ordenador donde se realiza la consulta). A diferencia del Quijote, cuyo CD-ROM contiene el texto de la obra maestra cervantina y el programa DBT (que permite construir concordancias y permite búsquedas por palabras o grupos de palabras, e incluso búsquedas secuenciales, de carácter gráfico, morfológico y estilístico), y varios índices (de todas las formas, inverso y directo, de localizaciones -index locorum); el CD de la CO no contiene programa de elaboración de concordancias, sino el resultado de esa elaboración, como documento de lectura ya hecho. El sistema de búsqueda se parece al de un diccionario enciclopédico tradicional: elegimos una letra, dentro de la cual se contienen, por orden alfabético, todos los lemas, a partir de los cuales accedemos al conjunto de ejemplos de cada forma. La disposición de las entradas es clara y las búsquedas resultan, merced a la eficaz interfaz y a su simplicidad, muy cómodas.

5 Pueden consultarse mediante concordance-builder las obras completas de San Ignacio de Loyola en CD-rom: Loyola (1996); además, está disponible la Concordancia ignaciana (Echarte 1996). 
El libro, por otro lado, contiene el artículo introductorio «De la elaboración y empleo de la Concordantia ortegiana» (pp. 13-36), el listado de siglas empleadas (pp. 39-201, con dos tablas de títulos -por tomos de Obras completas, pp. 41-121, y por orden alfabético, pp. 123201) y una presentación de la figura filosófica e histórica de Ortega y Gasset: «Ortega y los retos de la filosofía española», por Fernando-Miguel Pérez Herranz (pp. 203-247).

En el apartado «De la elaboración y empleo de la Concordantia ortegiana» explica el autor el proceso de gestación y confección de la obra: «Este trabajo supone la culminación de una labor desarrollada a lo largo de los últimos diez años» (p. 13), y es que ésta, como otras concordancias, es un trabajo ímprobo y, desde luego, encomiable. Es cierto, sin embargo, que se trata de un lapso de tiempo relativamente ajustado, impensable hace años, gracias a las modernas herramientas informáticas, y así lo reconoce el autor. En este caso el programa informático empleado es TACT (http://www.chass.utoronto.ca/tact), con el que se han elaborado también las concordancias de las obras completas de Benito Pérez Galdós. ${ }^{7}$

\subsection{MicROESTRUCTURA: LEMATIZACIÓN}

Los lectores de esta revista conocen ya con precisión las principales características de una concordancia lematizada. Fresnillo Núñez explica pormenorizadamente la labor de recopilación de ocurrencias y su lematización. ${ }^{8}$ Este procedimiento no es único del diccionario de lengua y de las concordancias lematizadas, sino que lo comparten enciclopedias e índices de los más variados tipos (onomástico, temático, topográfico...).

Así responde Fresnillo Núñez a la pregunta ¿Qué es lematización?: «Gramaticalmente, el proceso de lematización consiste en reducir las formas textualizadas a su forma base; pero los términos que se obtienen por mediación de los procedimientos descritos hasta aquí no se reducen a un simple listado de formas que se colocan linealmente por orden alfabético. Visto de esta manera parecería un simple diccionario, pero es algo más matizado...» (p. 12). Unas concordancias lematizadas son, en definitiva, un producto gramatical y lexicográfico.

\subsection{MACROESTRUCTURA: CONTENIDO Y ORDENACIÓN}

Por lo que respecta a la actual obra, el corpus de referencia es la edición de las Obras completas (en adelante $O C$ ) de 1983, texto del que se han subsanado unas 1200 erratas, según cuantificación del propio autor de la $C O$. En palabras suyas: «La edición de OCs es bastante deficiente.» (p. 15), y ejemplifica: los textos en griego ofrecen erratas muy abundantes -con nada fina ironía se habla de errores manifiestos-, hay bastantes ejemplos de italiagnolo -contaminaciones ortográficas del italiano por el español: bosquereccio por boschereccio-, nombres propios con varias grafías - Gengis Kahn con variantes: ¿cabe dudar que se pueden dar distintas transcripciones y trasliteraciones de idioma orientales?-, vulgarismos difícilmente atribuibles a Ortega-metereológico por meteorológico-... En resumen, erratas tipográficas en distinto grado o errores de las fuentes empleadas por Ortega: «Haría falta editar unas nuevas obras com-

7 El proyecto ya fue presentado hace un par de años en el número tres de la Revista de Estudios Orteguianos (2001), pp. 129-146; allí encontrará el lector más precisiones técnicas sobre el mismo. Es un proyecto relacionado con la Biblioteca Virtual Cervantes (http://www.cervantesvirtual.com), en la cual colaboró Fresnillo Núñez entre 1998 y 1999.

8 En el segundo punto 2, titulado «La lematización», del completo artículo introductorio «De la elaboración y empleo de la Concordantia ortegiana» (pp. 19-24). 
pletas, para poder averiguarlo en algunos casos; en otros - la mayoría - nos encontramos ante burdas erratas», concluye el propio Fresnillo (p. 17).

En cuanto a la ordenación de los lemas, que es alfabética, cabe destacar la separación en distintos lemarios de las diferentes lenguas que aparecen en el corpus textual de referencia. Por su especial dedicación a la divulgación científica y a la crítica literaria, Ortega y Gasset emplea en sus escritos abundantes neologismos y extranjerismos, muchos de los cuales pasarán a formar parte del acervo del vocabulario español según avance el siglo xx. Este rasgo estilístico implica, en la textualidad de su obra, una cierta abundancia de términos pertenecientes al léxico de lenguas diferentes al castellano; lo cual ha animado al autor de la concordantia a distinguir nueve lemarios además del principal, donde el lector puede buscar directamente los términos en alemán, catalán, griego, inglés, italiano, francés, latín, portugués y provenzal). Éstos se han construido a partir de diccionarios de cada una de las lenguas. Esta peculiaridad de la macroestructura permite la consulta del listado completo de términos no españoles que aparecen en las $O C$ de Ortega y Gasset, con las posibilidades que ello brinda al estudioso de los extranjerismos y neologismos contemporáneos.

\section{El vocabulario de Ortega y Gasset a través de la $C O$. Algunos ejemplos:} AMIBA, DE ANASTASIO

Para ilustrar las posibilidades de aprovechamiento de esta obra, realizaré un breve estudio lexicológico. Todos saben que Ortega fue un genio del lenguaje: creó, acuñó o tomó prestados términos nuevos que difundió o adaptó a la lengua española, dotándolos de sentido y forma escrita (o fónica) coherentes. Veamos el caso, por ejemplo, de dos términos que Ortega difundió y, quizás, acuñó: uno científico (ameba) y otro técnico (anastático) y observemos la información que nos ofrecen las concordantiae y las OC (2004-2008).

El DRAE-1947, que recoge todas las nuevas incorporaciones en un suplemento al final, fuera del orden alfabético del cuerpo principal, ${ }^{9}$ registra por vez primera la voz amiba, definida de este modo:

9 Han de tenerse en cuenta las especiales circunstancias históricas del momento para datar los nuevos aportes al vocabulario académico en la postguerra. El Diccionario de 1947 iba precedido de la siguiente «Advertencia», sin firma: «La edición 16. de este Diccionario, cuya impresión se terminó en 1936, aunque por haber estallado poco después la guerra civil, no llegara a ponerse en circulación hasta 1939, se ha agotado con más celeridad que de costumbre, a consecuencia sin duda de la destrucción de gran número de bibliotecas oficiales y particulares durante dicha guerra en la llamada «zona roja».

Este rápido agotamiento y la interrupción de la tareas académicas desde antes de estallar el conflicto hasta el restablecimiento de la normalidad tres años después, han sido causa de que los trabajos de revisión y acrecentamiento de esta obra fundamental no hayan podido llegar a su término en el momento en que convendría sacar a luz una nueva edición; pero, considerando la Academia que el mayor mal que podría originarse para el cumplimiento de su misión estatutaria para los estudiosos en general sería la absoluta carencia de ejemplares del Diccionario, ha decidido reimprimir el cuerpo de la obra según se halla en la edición 16. ${ }^{\mathrm{a}}$, añadiéndole, en un copioso suplemento, las novedades más importantes que se deducen de las recientes aportaciones y de los estudios ya efectuados, y dejando para más adelante las enmiendas introducidas en muchos artículos. Entonces habrá llegado la ocasión de utilizar, entre otras observaciones recibidas, las muy copiosas e interesantes que se ha dignado formular la Academia Argentina de Letras.

También se distingue de la precedente edición la que ahora se publica con el número XVII, porque en ésta se ha podido restablecer la costumbre tradicional de incluir en las páginas preliminares la relación de los individuos que forman parte». 
(Del gr. $\alpha \mu$ oı $\beta \eta$, fermentación). f. Zool. Protozoario unicelular provisto de seudópodos, que le sirven para moverse en el agua. (DRAE-1947S, s. v.). ${ }^{10}$

En el DMILE-1927 ya se daba cabida al tecnicismo amiba, aunque precedido de asterisco y con una remisión a amibo:

*AMIBA. f. Dígase amibo.

La definición de amibo resulta distinta de la del $D R A E-1947,{ }^{11}$ sin referencia a los seudópodos en el cuerpo, aunque sí en la ilustración que la acompaña:

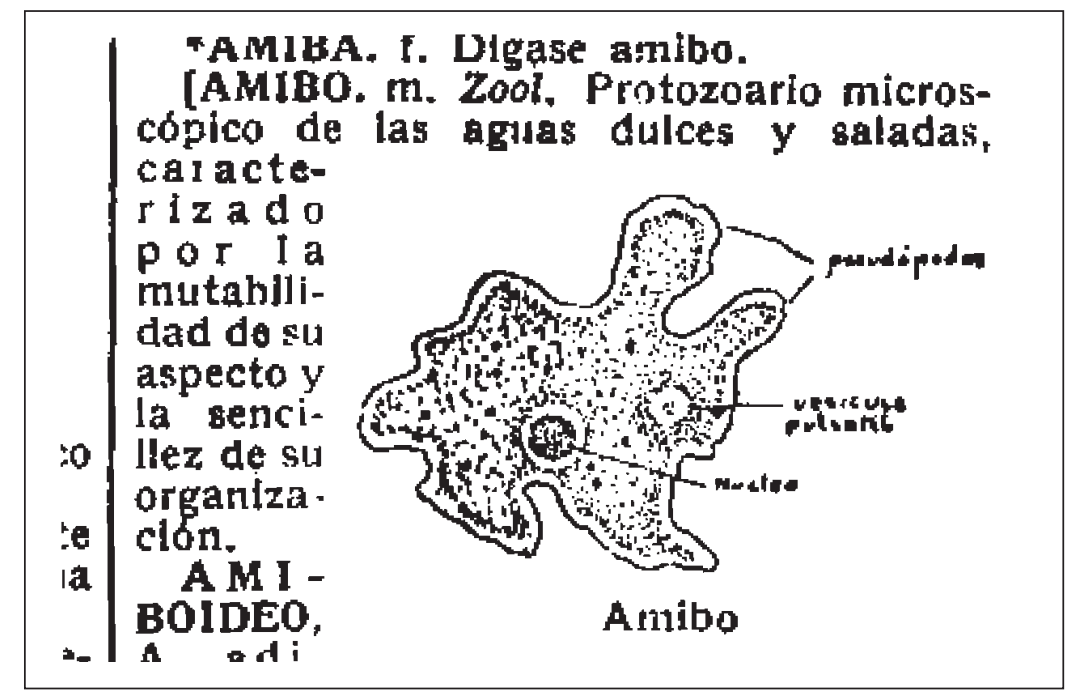

La forma moderna ameba se introduce en el $D R A E-1956$ :

Ameba. (Del gr. $\alpha \mu$ oı $\beta \eta$, cambio.) f. Zool. Protozoo rizópodo cuyo cuerpo carece de cutícula y emite seudópodos incapaces de anastomosarse entre sí. Conócense numerosas especies, de las que unas son parásitas de animales, otras viven en las aguas dulces y marinas y algunas en la tierra húmeda. || 2. f. pl. Zool. Orden de estos animales.

Y en el DMILE-1983, con la misma definición y ambas acepciones. A la vista de la cronología del término, cabe imaginar que la obra divulgativa de Ortega y Gasset tuviera algo que ver en la difusión y cambios formales del término: amibo (DMILE-1927, junto a seudópodo, y en $D R A E$-1956 con remisión ameba), > amiba (DMILE-1927, en el DRAE desde 1947 y desde 1956 con remisión a ameba) > ameba (en el $D R A E$ desde 1956, con la definición).

Según la $C O$, la única forma que aparece en las $O C$ de 1983, es ameba:

10 La voz seudópodo, incluida en la definición, se recoge a su vez en el cuerpo del diccionario. Fue incorporada por vez primera al vocabulario académico en el DRAE-1936 y en el DMILE-1950.

11 La forma incluida en la ilustración es pseudópodos, término que no aparece definido en el cuerpo del diccionario. La RAE lo incluirá entre las adiciones del vocabulario en 1936 (véase la nota siguiente). 


\section{Ameba (11)}

II,66,20(E16,F,C) los números», «la estrella más lejana de la tierra», «la ameba primera que existió»; pero sí veo, y porque lo veo

II,276,35(E21,E,Q,B) andar del hombre con la traslación del ser más elemental: la ameba. La ameba carece casi por completo de estructura; tiene

II,276,35(E21,E,Q,B) del hombre con la traslación del ser más elemental: la ameba. La ameba carece casi por completo de estructura; tiene órganos

II,277,3(E21,E,Q,B) reabsorberse en la masa total del organismo, y puede la ameba entregarse entera a la nutrición, sin tener que preocupar

II,277,14(E21,E,Q,B) fabulosas ventajas al pie y a la bicicleta. Por eso la ameba tiene una existencia mucho más segura que la del hombre

II,277,17(E21,E,Q,B) vida la prima mayor sería otorgada a la humilde ameba, mientras hoy se concede seguro al aviador.

II,277,19(E21,E,Q,B) se concede seguro al aviador. El andar de la ameba es, a un tiempo, creación del órgano adecuado y empleo de

II,277,34(E21,E,Q,B) fuerza genérica de motividad previa a toda organización. Lo que en la ameba se presenta a nuestros ojos acontece en todo organismo, bien

IX,24,23(IHU,1) cambia, mientras que un animal informe, sin órganos, como la ameba, tiene el poder de crearse en cada situación los

IX,24,40(IHU,1) para los novísimos problemas de aquel país; veremos si la ameba inglesa, en la apretada coyuntura presente, es capaz de largar

XII,399,22(IP,7) todos los números», «la estrella más lejana de la Tierra», «la ameba primera que existió», pero sí veo y porque lo

Estas ocurrencias demuestran que la aparición de la voz puede datarse entre 1915 (Investigaciones psicológicas -publicadas en 1982) y 1916 (El Espectador I, Filosofía, Conciencia, objeto y las tres distancias de éste) y 1948/49 -fecha de redacción-/1958 -fecha de publicación (Una interpretación de la historia universal). La mayoría de las ocurrencias (7/11) corresponden a El Espectador II (1921): «Ensayos filosóficos (Biología y Pedagogía), El Quijote en la escuela, La bicicleta, el pie y el seudópodo», serie de artículos en cuyo título aparece, precisamente, el término biológico seudópodo, con una historia paralela a la de la voz que analizamos. ${ }^{12}$ En conclusión, a la vista de los datos aportados por la $C O$, el término aparece preferentemente entre los años 1915 y 1921, ¿podríamos entonces datar su difusión en el léxico español hacia esas fechas?

El CORDE, un corpus con un concordance builder asociado, como hemos apuntado antes, arroja las siguientes ocurrencias:

Amibo (2 casos)

1 «Amibiosis. Enfermedad causada por un amibo, protozoo, localizado y denominado<» CABEZAS, Javier (1951): Cartilla del Colmenero, Madrid, Ministerio de Agricultura. Servicio de Capacitación y Propaganda.

12 En efecto, también seudópodo aparece por vez primera en español en los primeros años del siglo xx y su difusión pudo tener que ver con su aparición en $\mathrm{El} \mathrm{Sol}$, en el título y en el cuerpo de algunos de los artículos de esta serie. En aquella ocasión Ortega utilizó la forma pseudopodio, que no triunfará, y que ya en 1921 corrige por pseudópodo. El CORDE arroja las siguientes primeras documentaciones de la forma pseudópodo: Ignacio Bolívar (1909): Zoología, Madrid, Imprenta Fortanet; Enrique Rioja Lo-Bianco (1926): Los protozoos, Barcelona, Instituto Gallach de Librería y Ediciones. Este último autor registra los más antiguos casos de la forma amiba. El DRAE recoge seudópodo desde 1936. 
2 «Ya habeis escuchado al capitan, dijo mi $a m i b o^{13}$ Quilalebo, y me parece que no teneis qué replicar...» NúÑEZ DE PINEDA Y BASCUÑán, Francisco (1673): El cautiverio feliz, Santiago de Chile, Imprenta del Ferrocarril, 1863.

Amiba (25 casos en 11 documentos), los más antiguos de 1926 y 1935 :

Rioja Lo-Bianco, EnRiQue (1926): Los protozoos, Barcelona, Instituto Gallach de Librería y Ediciones (11 casos) y ANÓNIMO (1935): El carbarsone en el tratamiento de la amibiasis, Costa Rica, Ciencia. Revista científico literaria.

Ameba (60 casos en 9 documentos), estos son los ejemplos hasta 1943:

1 ...y más libre la célula animal, a modo de ameba -el glóbulo de la sangre nos ofrece un caso de... Unamuno, Miguel de (1902): Amor y pedagogía, Ricardo Senabre (ed.), Madrid, Turner, 1995.

2 «La Muerte, ¿es distinta del Amor? Para la ameba morir es reproducirse.» A sus pies lee... Unamuno, Miguel de (1902): Amor y pedagogía, Ricardo Senabre (ed.), Madrid, Turner, 1995.

3 se liberta alguna de mis células y convertida en ameba se propaga y propaga consigo mi conciencia? Unamuno, Miguel de (1902): Amor y pedagogía, Ricardo Senabre (ed.), Madrid, Turner, 1995.

4 «la estrella más lejana de la tierra», «la ameba primera que existió»; pero sí veo... ORTEGA Y GASSET, José (1916): El espectador, I Madrid, Alianza Editorial-Revista de Occidente, 1993.

5 ...queda aprisionada en el citoplasma de la ameba dentro de una gota de agua, la cual viene a... Fernández Galiano, Emilio (1929) Los fundamentos de la biología, Barcelona, Labor, 1939 (sic).

6 Fig. 65. Naegleria (ameba) emitiendo varios pseudópodos. (De Wasielewski) FernÁndEz GALiAnO, EMilio (1929): Los fundamentos de la biología, Barcelona, Labor, 1939 (sic).

7 ...después de lo cual se encorva la ameba y comienza a arrollar el filamento sobre sí... Fernández Galiano, Emilio (1929): Los fundamentos de la biología, Barcelona, Labor, 1939 (sic).

8 por quedar arrollado dentro del citoplasma de la ameba. Fig. 68. Ameba apoderándose de una partícula... Fernández GALIANO, EMilio (1929): Los fundamentos de la biología, Barcelona, Labor, 1939 (sic).

9 ...Fig. 69. Una ameba apoderándose de un filamento de alga. Fernández Galiano, Emilio (1929): Los fundamentos de la biología, Barcelona, Labor, 1939 (sic).

10 La figura 141 representa una ameba en el interior de cuyo citoplasma habitan... FERNÁndEZ Galiano, Emilio (1929): Los fundamentos de la biología, Barcelona, Labor, 1939 (sic).

11 ...no cabe duda, por consiguiente, de que esta ameba, a pesar de ser tan semejante a la inofensiva... Fernández Galiano, Emilio (1929): Los fundamentos de la biología, Barcelona, Labor, 1939 (sic).

12 ...una partícula extraña se pone en contacto con una ameba prodúcese en el punto correspondiente... FernÁNDEZ Galiano, Emilio (1929): Los fundamentos de la biología, Barcelona, Labor, 1939 (sic).

13 B) Protozoarios. 1. El principal es la ameba disentérica (entameba histolítica). MARAÑón, Gregorio (1943): Manual de diagnóstico etiológico, Madrid, Espasa Calpe, S.A., 1943. 
14 2. La ameba coli, muy frecuente, no tiene interés patógeno. MARAÑón, GrEGORIO (1943), Manual de diagnóstico etiológico, Madrid, Espasa Calpe, S.A., 1943. ${ }^{14}$

El muestrario ofrece datos bastante significativos sobre la evolución formal del tecnicismo, con una aparente pugna entre la forma que ha triunfado hoy en día (ameba, que es la más antigua y frecuente) y aquellas que han quedado relegadas en el diccionario académico: amibo (un solo ejemplo de 1951) y amiba (relativamente frecuente desde 1926 en textos científicos, y a partir de los cincuenta en textos literarios. ${ }^{15}$

En su última publicación, el Diccionario panhispánico de dudas, la Real Academia Española y la Asociación de Academias de la Lengua Española recomiendan el empleo de la forma ameba, pues recoge amiba con una remisión a aquélla. La definición explica:

ameba. 'Protozoo unicelular': «Al analizar sus heces se encontraron abundantes amebas» (Vijnovsky Dudas [Arg. 1988]). Esta es la forma usada mayoritariamente en todo el ámbito hispánico, salvo en México, donde se emplea la variante amiba: «La amiba no tiene forma, parece una gota de gelatina suave» (Gánem Caminitos [Méx. 2001]).

Parece, por tanto, que nos encontramos ante dos formas cuyas peculiaridades de uso tienen que ver no sólo con cuestiones diacrónicas, según trasparece de los datos recogidos en el $C O R D E$, sino también diatópicas, pues se ha producido una escisión entre el español de México y el del resto de los territorios hispanoparlantes. ${ }^{16}$

Regresemos pertrechados de estos datos a las $O C$ de Ortega, en su segundo tomo encontramos los casos de los primeros años, especialmente significativos los de «El Quijote en la escuela». En el parágrafo «La bicicleta, el pie y el pseudópodo» tenemos este pasaje donde se asocian, como en el epígrafe, ameba y pseudópodo:

14 Consulta del 25 de noviembre de 2005. Son especialmente significativos los ejemplos científicos de Gregorio Marañón, cuya actividad en la Academia fue fundamental para la corrección e inclusión de términos médicos y biológicos en las ediciones del DRAE de 1936, 1947 y 1956. La ocupación de Marañón en la Real Academia Española fue continua desde su ingreso en 1934 y su fallecimiento en 1960. López Vega ha señalado tres momentos en los que aflora su interés por mejorar el tratamiento lexicográfico y el número de tecnicismos médicos y biológicos en el diccionario general: 1934, cuando muestra, en carta al director Ramón Menéndez Pidal, su «enojo» al no incluirse en las pruebas de la nueva edición del DRAE sus propuestas aprobadas por la comisión; 1946, en el «discurso de contestación al de ingreso de Esteban Terradas en la Corporación»; y, por último, en una nota sin fecha que señala las voces corregidas en el Diccionario en las que había participado, que podría datarse después de 1956, «puesto que algunas de las voces que incluye están recogidas en la edición de ese año» (2004: 220).

15 Carmen Martín Gaite (1958): Entre visillos, Barcelona, Áncora y delfín; Carlos Fuentes (1994): La muerte de Artemio Cruz, Madrid, Anaya-Muchnik; José Lezama Lima (1988): Paradiso, Madrid, CSIC y Arturo Azuela (1985): El tamaño del infierno, Jorge Rodríguez Padrón, Madrid, Cátedra.

16 En consulta realizada el 21 de diciembre de 2005, el CREA de la Real Academia Española, mostraba cuatro casos de la forma amiba: Eloísa Valdivieso (1988): Cómo aliviarse de la panza, Árbol (México D.F.); Guadalupe Ana María Vásquez Torre (1993): Ecología y formación ambiental, MCGraw-Hill Interamericana de México (México); Enrique Gánem (2001): Caminitos de plata. 100 cápsulas científicas, McGraw-Hill Interamericana Editores (México D.F.); Alejandro Jodorowsky (1994): Donde mejor canta un pájaro, Seix Barral (Barcelona). Los tres textos científicos, con un ejemplo cada uno, fueron editados en México; el único caso no mexicano aparece en una novela del chileno Alejandro Jodorowsky Prullansky, nacido en 1929, hijo de emigrantes rusos [http://www. clubcultura.com/clubliteratura/clubescritores/jodorowsky/bio.htm]. La forma ameba, en consulta de la misma fecha, presentaba 43 casos en 24 documentos: 26 en documentos españoles, 8 chilenos, 5 cubanos y 4 argentinos. 
Compárese el andar del hombre con la traslación del ser más elemental: la ameba. La ameba carece casi por completo de estructura; no tiene órganos especializados en funciones determinadas. Cuando quiere desplazarse hace avanzar su protoplasma en la dirección deseada, formando una especie de tentáculo o prolongación. Fabrica, pues, un pie momentáneo y ad hoc, que se tiende hacia el sitio ambicionado. Por contracción elástica, este casi pie o pseudópodo arrastra el resto del cuerpo amíbico. (p. 404).

Como se nos informa en la «Noticia bibliográfica» del mismo tomo II, la serie en cuestión fue publicada entre el 16 de marzo de 1920 y el 22 de junio del mismo año, con títulos diferentes, con o sin numeración. ${ }^{17}$

En la página 144 de este mismo volumen, en «Conciencia, objeto y las tres dictancias de éste (fragmentos de una lección)», encontramos también el primer ejemplo del término en la obra de Ortega, de 1915, que corresponde a un curso impartido entre el otoño de 1915 y marzo de 1916 en el Centro de Estudios Históricos, publicado póstumamente como Investigaciones psicológicas, en 1982, con el mismo ejemplo de ameba.

En resumen, parece posible afirmar que Ortega usa ameba con frecuencia, tanto en sus cursos impartidos oralmente, como en la prensa, y en el Espectador, I y III, a pesar de que por entonces no fuera un término frecuente, o quizás por eso precisamente. Como se nos advierte en el prólogo a la nueva edición de las $O C$, el texto de los distintos pasajes se ha fijado a partir de la última publicación en vida del autor, en este caso la de las $O C$, tercera edición, de 1955; por tanto, hemos de recurrir al apéndice de variantes para poder conocer qué decía Ortega en el periódico de 1920.

No obstante, como también se dice en el prólogo, no podremos allegar allí variantes correspondientes a «los cambios gramaticales de menor entidad (ortográficos — fué>fue, amiba>ameba -; morfológicos — morfología flexiva: género, número, tiempo, modo, aspecto-, y sintácticos — cambios de número o de género que afectan a las concordancias pero no al sentido)». En definitiva, hemos de recurrir a los documentos originales.

En El Sol del 16 de marzo de 1920 escribía Ortega:

Compárese el andar del hombre con la traslación del ser más elemental: la amiba. La amiba carece casi por completo de estructura; no tiene órganos especializados en funciones determinadas. Cuando quiere desplazarse hace avanzar su protoplasma en la dirección deseada, formando una especie de tentáculo o prolongación. Fabrica, pues, un pie momentáneo y "ad hoc", que se tiende hacia el sitio ambicionado. Por contracción elástica, este casi pie o pseudopodio arrastra el resto del cuerpo amíbico.

Y así continua el uso orteguiano hasta 1950, cuando la segunda edición de $O C$ cambia sistemáticamente amiba por ameba, siguiendo así la prescripción académica recién estrenada entonces. Eso supone que Ortega ha escrito y publicado amiba hasta entonces, es decir: en 1921 (El Espectador III, 1. . ed.), 1928 (El Espectador III, 2. ${ }^{\text {e }}$ ed.), 1933 (El Espectador I- III), en 1943 (El Espectador [I-VIII]), en 1932, 1936, 1943 (en las tres ediciones de Obras), y en 1946 (Ortega

17 «Biología y pedagogía o el "Quijote” en la escuela», El Sol, 16-III-1920.*; «Biología y pedagogía o el "Quijote” en la escuela. Continuación», El Sol, 18-III-1920.*; «Pedagogía de secreciones internas I», El Sol, 26-III-1920.*; «Pedagogía de secreciones internas II», El Sol, 1-IV-1920.*; «Biología y pedagogía o el "Quijote” en la escuela I», El Sol, 18-VI-1920.*; «Biología y pedagogía o el "Quijote” en la escuela II», El Sol, 22-VI-1920.* 
y Gasset 1946-1947). En conclusión, lo que aparentaba ser una fluctuación entre dos formas contemporáneas, resulta ser más bien un proceso de adaptación explicable como la sustitución de amibo por amiba y, después, de amiba por ameba. ${ }^{18}$

Este caso prueba, más allá de la posibilidad de acumular datos sobre cualquier ítem léxico presente en el corpus de la obra orteguiana, que las herramientas disponibles, $O C$ (Ortega y Gasset 1946-1947¹), CO y OC (Ortega y Gasset 2004-2008) no evitan, si se quiere hacer un estudio a fondo y preciso sobre el uso lingüístico de Ortega, la consulta de los documentos originales de primera mano, pues tanto las ediciones de obras como las concordancias - cuya base son las $O C$ de 1983, no lo olvidemos-, no pretenden ser exhaustivas, no tanto en la recolección de los datos, como en su presentación. La nueva edición de las $O C$ se ha planteado con unos límites muy claros: evitar en ningún caso dificultar el acceso cómodo de los lectores del filósofo madrileño, y seleccionar sólo la información más relevante e imprescindible para hacer una lectura cronológica del corpus orteguiano. La decisión de dejar fuera las variantes ortográficas halla así su explicación en estos límites; ahora bien: la inclusión de la información documental en la «Noticia bibliográfica» permite, partiendo del tomo II de la nueva edición, realizar la indagación documental pertinente para calibrar la exactitud de una afirmación como: «Ortega y Gasset utilizó en 1920 la forma ameba del conocido tecnicismo biológico entonces un neologismo orteguiano». ${ }^{19}$

18 Esta conclusión debe atenuarse al comprobar la primera documentación, en «Conciencia, objeto y las tres distancias de éste», del término biológico: «Yo no veo ahora ni acierto a representarme "el número que contiene todos los números", "la estrella más lejana de la tierra", "la ameba primera que existió"...»; por tanto, parece que Ortega escribió, desde primera hora, ameba en este pasaje. Por otra parte, el caso paralelo seudópodo presenta una cronología similar a la de ameba en la obra orteguiana:

II,275,2(E21,E,Q,B) pedagogía. LA BICICLETA, EL PIE Y EL PSEUDÓPODO No todas las funciones vitales, corporales o

II,276,40(E21,E,Q,B) Por contracción elástica, este casi pie o pseudópodo arrastra el resto del cuerpo amíbico. Llegar al lugar

II,277,1(E21,E,Q,B) resto del cuerpo amíbico. Llegar al lugar apetecido y desaparecer el pseudópodo son una misma cosa. Una vez utilizado, viene

II,277,6(E21,E,Q,B) mismos, constituyen una carga para el estómago. El pseudópodo es, por tanto, un órgano que sólo existe en tanto y

II,277,11(E21,E,Q,B) muy precisas, sirven la función de andar mucho mejor que el pseudópodo; pero fuera de ellas sirven para poco o

II,277,13(E21,E,Q,B) balance que la vida hace de sus cuentas milenarias, el pseudópodo lleva fabulosas ventajas al pie y a la bicicleta. Por

IX,24,25(IHU,1) al alimento emite de su plasma una prolongación o pseudópodo que funciona como un pie que la hace caminar y, una

IX,24,41(IHU,1) inglesa, en la apretada coyuntura presente, es capaz de largar los oportunos pseudópodos. Vamos ahora a

No aparece en las $O C$ de 1983 la forma pseudopodio, según la $C O$, que es la que leemos en El Sol en marzo de 1920. En este caso, la forma primera creada por Ortega, también un neologismo, es pseudopodio, que pronto se sustituye por pseudópodo a partir de la inclusión del ensayo en El Espectador, III.

19 A la vista del dato del CORDE que indica que la primera documentación de la voz aparece en Amor y Pedagogía, de Unamuno (1902), y del análisis que hemos hecho de los casos recogidos en el corpus orteguiano, no podríamos aseverar que el rector salmantino usase la forma ameba, al menos sin conocer de primera mano los criterios que Ricardo Senabre ha empleado para la fijación de la ortografía de su texto. 
El otro caso que analizaremos para mostrar la potencialidad de las nuevas herramientas al alcance del estudioso de la lengua de Ortega y de la Edad de Plata, en general, es el del tecnicismo de anastasio, traducción del alemán anastatische, que designa un tipo de reproducción gráfica:

En sus comienzos padece un positivismo o biologismo algo superficial, que pronto corrige. Después de su Introducción a la ciencia moral: 1892 -que no quiso reeditar sino en impresión de anastasio- y de los problemas de la filosofía de la historia... («Jorge Simmel», tomo III, p. 742. Nota final redactada por Ortega para la Filosofía de la coquetería; Filosofía de la moda; Lo masculino y lo femenino, de Jorge Simmel, publicada por Revista de Occidente en 1924, pp. 229-230, véase Noticia bibliográfica, Obras completas, tomo III, p. 964).

Para este ejemplo ni los diccionarios académicos, ni el CREA o el CORDE nos serán de ayuda, pues no aparece ninguna ocurrencia de la expresión de anastasio, la que emplea Ortega en el pasaje citado, ni anastático, la otra forma esperable. ${ }^{20}$

Por su lado, la $C O$ nos ofrece dos ejemplos del helenismo anastasia, ambos en el mismo texto, pero no aporta ejemplos ni de anastasio ni de anastático. Veamos el fragmento con la explicación de Ortega:

Aristóteles, al preguntarse cuál es el propósito y designio de la ciencia política, se reponde no ser otro que hallar los medios para conseguir la «anastasia». La «anastasia» no es, como de primera intención pudiera creerse, una buena moza de los Madriles, sino lo contrario de la «estasia»: es la estabilidad.

Es evidente, por tanto, que el germano anastatische se relaciona con el griego anastasia, y que Ortega conoce perfectamente el étimo del tecnicismo alemán. ¿Por qué no recurre entonces al derivado paralelo español anastático y prefiere de anastasio? La respuesta está, sin duda, en el profundo dominio y conocimiento que Ortega tiene de la lengua española, sus mecanismos de adaptación de préstamos léxicos y las estructuras morfosintácticas equivalentes del español y el alemán, lengua que también conocía muy bien don José. De modo que Ortega, que era libre para adaptar el préstamo a su gusto, prefirió el sintagma preposicional [de + sustantivo] que el adjetivo derivado a partir de Anastasio, es decir: anastático. Lamentablemente en este caso ni el CORDE, ni los diccionarios académicos, ni la $C O$, nos ayudan a aclarar este asunto; la nueva edición de $O C$, que incluye el texto en cuestión, reeditado en 1982 por vez primera desde su aparición original en 1924 y jamás incluido en ediciones anteriores de las obras de Ortega, nos pone sobre la pista de su explicación. En conclusión, de nuevo se muestra que es necesario, antes de realizar afirmaciones tajantes consultar los documentos disponibles, y en este caso el manuscrito, que incluye la clave para la interpretación del préstamo y su ortografía.

20 En el manuscrito de esta nota, conservado en el Archivo de la Fundación José Ortega y Gasset, se lee claramente la minúscula: «de anastasio», aunque en el libro de 1924 apareció como nombre propio en mayúscula. Paulino Garagorri reprodujo la nota en: Kant, Hegel, Scheler, Madrid, Revista de Occidente en Alianza Editorial, 1983, p. 137-138, con minúscula: de anastasio. 


\section{CONCLUSIONES}

Los análisis de este tipo podrían multiplicarse, sin necesidad de restringirlos al registro científico y técnico, pues aparecen casos en todos los niveles de lengua. En el caso de las sustituciones léxicas, es muy ilustrativo el de coger y prender, empleados muchas veces como sinónimos en los textos de Ortega. Si nos remitimos a las concordancias lematizadas, las formas de prender (106) superan a las de coger (55); para considerar si se trata de sinónimos perfectos en más o menos de esos casos, habría que analizar cada uno de los ejemplos, estudio que rebasa los límites que nos hemos planteado en este trabajo. Ahora bien, si buscamos estos verbos en el apéndice de variantes de las nuevas $O C$, que en este caso sí deberían incluir los casos de variación por tratarse de sustituciones léxicas y no de cuestiones menores, recogemos este ejemplo en el apéndice del tomo II:

Pág. 689, líneas 39-40 «...-coger algo, acercarse, huir-...».

LN (9-VIII-25) «...-prender algo, acercarse, huir-...».

El ejemplo es obvio, la sustitución de coger por prender en La Nación de Buenos Aires del 9 de agosto de 1925, en «Sobre la expresión, fenómeno cósmico», viene motivada por tratarse el primero de los verbos de una palabra malsonante en América. Este cambio, incluso, podría achacársele al tipógrafo o corrector del diario bonaerense. Evidentemente, el ejemplo de La Nación no es considerado en las concordancias por su limitación al texto de las $O C$ de 1983. No parece necesario multiplicar los ejemplos para mostrar la importancia, junto a las nuevas herramientas presentadas, del conocimiento directo de los documentos, de los textos en sus fuentes originales.

A pesar de todo ello, es necesario decir que el análisis lingüístico (lexicológico concretamente) del texto orteguiano de la nueva edición de las $O C$ se facilita enormemente con esta herramienta lexicográfica novedosa, la $C O$ de la que nos hemos ocupado, cuyos principales méritos y aportaciones al conocimiento del vocabulario y la lengua del mayor filósofo español del Veinte pueden resumirse en la corrección de numerosas erratas y su presentación en soporte electrónico, que permite la combinación de los datos aportados por ella con otros procedentes de fuentes lexicográficas diversas, como hemos tratado de mostrar en los casos analizados, como ejemplos, en este trabajo.

\section{REFERENCIAS BIBLIOGRÁFICAS}

CARPI, Elena (2002): El léxico del quatripartitu en cosmografía práctica de Alonso de Chaves, Madrid, Universidad Nacional de Educación a Distancia.

(2004): El léxico de la suma de geographía de Martín Fernández de Enciso, Madrid, Universidad Nacional de Educación a Distancia.

CORDE. ReAl ACADEMIa Española: Corpus diacrónico del español (www.rae.es).

CREA. Real ACADEMIa Española: Corpus de referencia del español (www.rae.es). 
DMILE-1927. Real ACAdemia Española (1927): Diccionario manual e ilustrado de la lengua española, Madrid, Espasa-Calpe.

DMILE-1950. ReAl ACADEMIA Española (1950): Diccionario manual e ilustrado de la lengua española, Madrid, Espasa-Calpe.

DMILE-1983. ReAl ACADEMIA Española (1983): Diccionario manual e ilustrado de la lengua española, Madrid, Espasa-Calpe.

DRAE-1936. ReAl ACAdEMia Española (1936 $\left.{ }^{16}\right)$ : Diccionario de la lengua española, Madrid, EspasaCalpe.

DRAE-1947. Real ACAdemia Española (194777): Diccionario de la lengua española, Madrid, EspasaCalpe.

DRAE-1956. ReAl ACADEMia Española (1956 $\left.{ }^{18}\right)$ : Diccionario de la lengua española, Madrid, EspasaCalpe.

ECHARTE, Ignacio, ed. (1996): Concordancia ignaciana, Santander, Editorial Sal Terrae.

FRESNILLO NúÑEZ, J. (2004): CONCORDANTIA ORTEGIANA. Concordantia in José Ortega y Gasset opera omnia, con la colaboración de Fernando Miguel Pérez Herranz, Alicante, Universidad de Alicante.

GARAGORRI, Paulino (1983): Kant, Hegel, Scheler, Madrid, Alianza Editorial.

GARCíA-MACHO, Lourdes (1996): El léxico castellano de los Vocabularios de Antonio de Nebrija (concordancia lematizada), Hildesheim, Olms-Weidmann.

(2004): El léxico de la instrucción náuthica para el buen uso y regimiento de las naos, su traça y govierno conforme a la altura de México de Diego García de Palacio, Madrid, Universidad Nacional de Educación a Distancia.

Iso, J. J. (1987): La Peregrinatio egeriae: una concordancia, Zaragoza, Universidad de Zaragoza.

(1991): Index verborum y concordancia institutiones oratoriae Quintiliano, Bellaterra, Universitat Autònoma de Barcelona.

LÓPez VegA, Antonio (2004): «Aportación al vocabulario científico técnico de Gregorio Marañón», Cuadernos de historia contemporánea, 26, pp. 215-225.

LoYola, Ignacio de (1996): Polanco. The writings of Saint Ignatius of Loyola, The Institute of Jesuit Sources, Saint Louis [CD-ROM, pre-release version 0.9].

Magallón García, Ana Isabel (1993): Concordancia lematizada de los itinerarios de Egeria y Antonino, Zaragoza, Universidad de Zaragoza.

ORTEGA Y GASSET, José (1946-1947¹): Obras completas, Madrid, Revista de Occidente, vols. I-VI.

_ (1983): Obras completas, ed. Paulino Garagorri, Madrid, Alianza Editorial, vols. I-XII.

(2004-2008): Obras completas, ed. Carmen Asenjo, Ignacio Blanco, Cristina Blas, José Ramón Carriazo, Iñaki Gabaráin, Isabel Ferreiro, Patricia Giménez, Felipe González, Alejandro de Haro, Azucena López, Juan Padilla y Javier Zamora, Madrid, Taurus y Fundación Ortega y Gasset., vols. I-VIII.

Real Academia Española y Asociación de Academias de la Lengua (2005): Diccionario panhispánico de dudas, Madrid, Santillana.

Saba, Antonina (2002): El léxico del breve compendio de la Sphera y del arte de navegar de Martín Cortés, Madrid, Universidad Nacional de Educación a Distancia.

(2004): El léxico del compendio de la arte de navegar de Rodrigo Zamorano, Madrid, Universidad Nacional de Educación a Distancia. 
Spevack, Marvin (1973): The Harvard concordance to Shakespeare, Cambridge (Mass.), Harvard University Press.

WARWICK, Henrietta Holm (1975): A Vergil concordance, Minneapolis, University of Minnesota Press.

Wilkins, Ernest H. y Thomas G. Bergin (1965): A Concordance to the Divine Comedy, Cambridge (Mass.), Harvard University Press.

YAGÜE FERRER, María Isabel (1995): Jaca, documentos municipales (971-1324): Introducción y concordancia lematizada, Zaragoza, Universidad de Zaragoza. 